\title{
A Novel Architecture for 10-bit 40MSPS Low Power Pipelined ADC using Simultaneous Capacitor and Op-amp Sharing Technique
}

\section{Shylu Sam ( $\sim$ mail2shylu@yahoo.com )}

Karunya Institute of technology and Science: Karunya Institute of Technology and Sciences https://orcid.org/0000-0001-5559-0202

D. Jackuline Moni

Karunya Institute of technology and Science: Karunya Institute of Technology and Sciences

P.Sam Paul

Karunya Institute of technology and Science: Karunya Institute of Technology and Sciences

D. Nirmal

Karunya Institute of technology and Science: Karunya Institute of Technology and Sciences

\section{Research Article}

Keywords: op-amp,capacitor sharing, power consumption, Dynamic comparator, Analog to Digital converter (ADC)

Posted Date: April 26th, 2021

DOl: https://doi.org/10.21203/rs.3.rs-422594/v1

License: (c) (1) This work is licensed under a Creative Commons Attribution 4.0 International License. Read Full License

Version of Record: A version of this preprint was published at Silicon on July 21 st, 2021 . See the published version at https://doi.org/10.1007/s12633-021-01241-x. 


\title{
A novel architecture for 10-bit 40MSPS low power Pipelined ADC using simultaneous capacitor and op-amp sharing technique
}

\author{
D.S.Shylu ${ }^{1}$ D.Jackuline Moni ${ }^{2}$ P.Sam Paul ${ }^{3}$ D.Nirmal ${ }^{4}$ \\ Associate Professor ${ }^{1}$, Professor ${ }^{2}$, Associate Professor ${ }^{4}$ Department of Electronics \& Communication Engi- \\ neering, Karunya Institute of Technology and Sciences, Coimbatore, 641114, Tamil Nadu, \\ India.Phone:9487224478.e-mail: mail2shylu@yahoo.com,moni@karunya.edu,nirmal@karunya.edu \\ ${ }^{3}$ Professor, Department of Mechanical Engineering, Karunya Institute of Technology and Sciences, Coimba- \\ tore, 641114, Tamil Nadu, India \\ E-mail: psam_paul@rediffmail.com.
}

\begin{abstract}
This work presents a low power 10-bit 40 MSPS Pipelined ADC with 1.8V supply voltage in a $180 \mathrm{~nm}$ silicon based CMOS process. Simultaneous capacitor sharing and op-amp sharing technique is used between two successive stages of a Sample-and Hold Ampifier (SHA) to reduce the power consumption.The memory effect in the proposed $\mathrm{ADC}$ is eliminated by a low input capacitance variable $\mathrm{g}_{\mathrm{m}} \mathrm{op}$-amp. The differential and integral nonlinearity of the converter are within LSB.Simulation results show that the required Signal-Furious-Dynamic range (SFDR) of 70dB, Signal-to -Noise-plus Distortion Ratio (SNDR) of 56.1dB and 9.02 Effective Number of Bits ( ENOB ) has been achieved with a $2 \mathrm{MHz}, 1-\mathrm{V}_{\mathrm{p}-\mathrm{p}, \mathrm{diff}}$ input signal while consuming only $7.3 \mathrm{~mW}$ power from $1.8 \mathrm{~V}$ supply.
\end{abstract}

Keywords: op-amp,capacitor sharing, power consumption, Dynamic comparator, Analog to Digital converter (ADC)

\section{Introduction}

With the increasing demand for the Application Specific Integrated Circuits (ASICs) there is a wide development of mixed-signal design, compatible with System-on-chip $(\mathrm{SoC})$. Data converters have become an important block in SoC design for data communication and image processing applications [1].Among the different ADC design pipelined ADCs are suitable for high speed,medium resolution and low power applications [2-4].Since the accuracy decreases in the later stages of pipeline ADC, proper scaling of capacitors are required in pipelined ADC [5-7]

Sharing an op-amp between two consecutive stages can further reduce power consumption [8-10]. Furthermore switched-op-amp techniques[ 11-12] was proposed to reduce the power consumption of pipelined ADC. The maximum power is consumed in the first stage of the pipelined ADC [12].

To reduce the power consumption of ADC capacitor sharing technique was proposed [13-16]. To further reduce the power consumption, the front-end sample and hold circuit $(\mathrm{S} / \mathrm{H})$ is eliminated [17-18].SHA introduces additional noise signal which is integrated to the analog signal and results in large power dissipation and occupies more die area. Also the $\mathrm{S} / \mathrm{H}$ circuit is removed by integrating the SHA in first stage of pipeline ADC to reduce the power[19]. Hence it is essential for certain applications to simplify the pipelined ADC 
by eliminating the supplementary blocks such as SHA circuit [20]. The aperture error is reduced by matching the delays that occur between the sampling networks of the subblocks including first MDAC and comparators [21]. In this paper, a novel SHA-less pipelined ADC using a combination of simultaneous capacitor and amplifier sharing with a sampling frequency of 40 MSPS is presented. To achieve low- power and high performance, the $\mathrm{P}$-gain and $\mathrm{N}$-gain boosted variable $\mathrm{g}_{\mathrm{m}}$ op-amp and dynamic comparators have been designed.

\section{Architecture of SHA-less Pipelined ADC}

The proposed SHA-less Pipelined ADC architecture is shown in Fig.1. It mainly contains a SHA-less front-end followed by second stages in which two op-amps are shared in neighboring stages followed by 3-bit Flash ADC. In order to limit the overall conversion rate the bandwidth of the Switched Capacitor (SC) circuit is to be maximized. The closedloop gain of the amplifier is 2 so that a large feedback factor and a low load capacitance is achieved. Since the capacitance load is very less and the feedback factor is large the bandwidth of the amplifier which is used in the intermediate stages can be increased. Fig. 2 shows the first and second stages of the ADC.

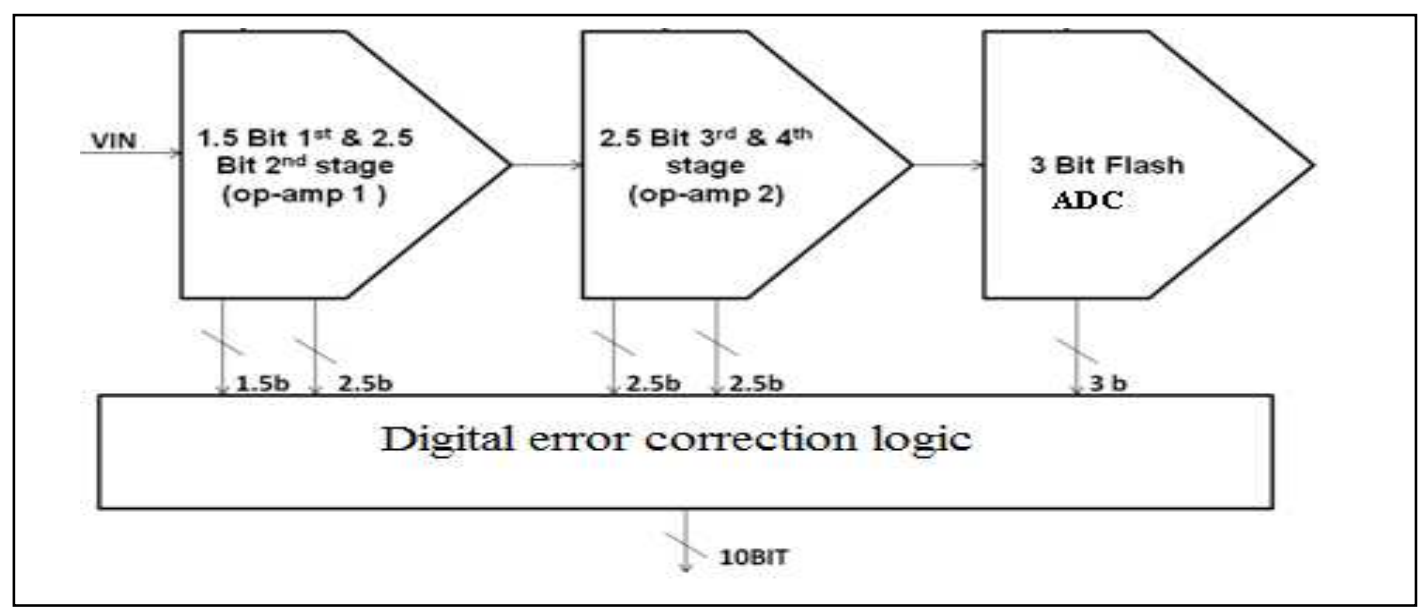

Fig. 1 A 10-bit SHA-less Pipelined ADC structure 


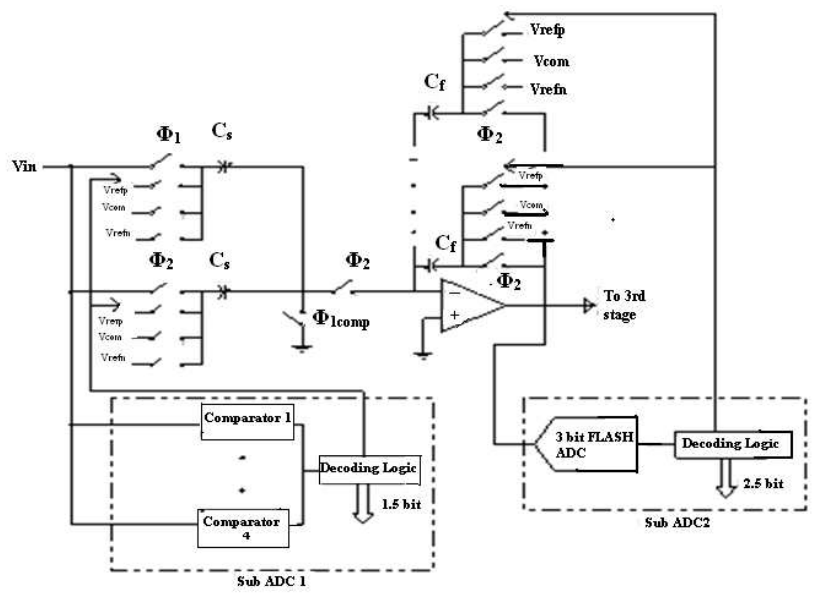

Fig. 2 First and second stages of 10-bit Pipelined ADC

\subsection{Operational amplifier}

An op-amp is the main important sub-circuit of analog systems[22-25]. The common mode noise and even harmonics are reduced in the fully differential amplifier which employs a two-stage topology when compared with the single ended output op-amp. Also the linearity is increased in the fully differential amplifier. Fig. 3 shows the designed two-stage fully differential OTA which uses the gain boosted auxiliary amplifier. Here the fully differential structures are used in $\mathrm{P}$ gain boost and $\mathrm{N}$ gain boost amplifiers. With $1.8 \mathrm{~V}$ supply voltage the gain boosted amplifier is simulated initially to verify the desired specifications which was described by [26-28].

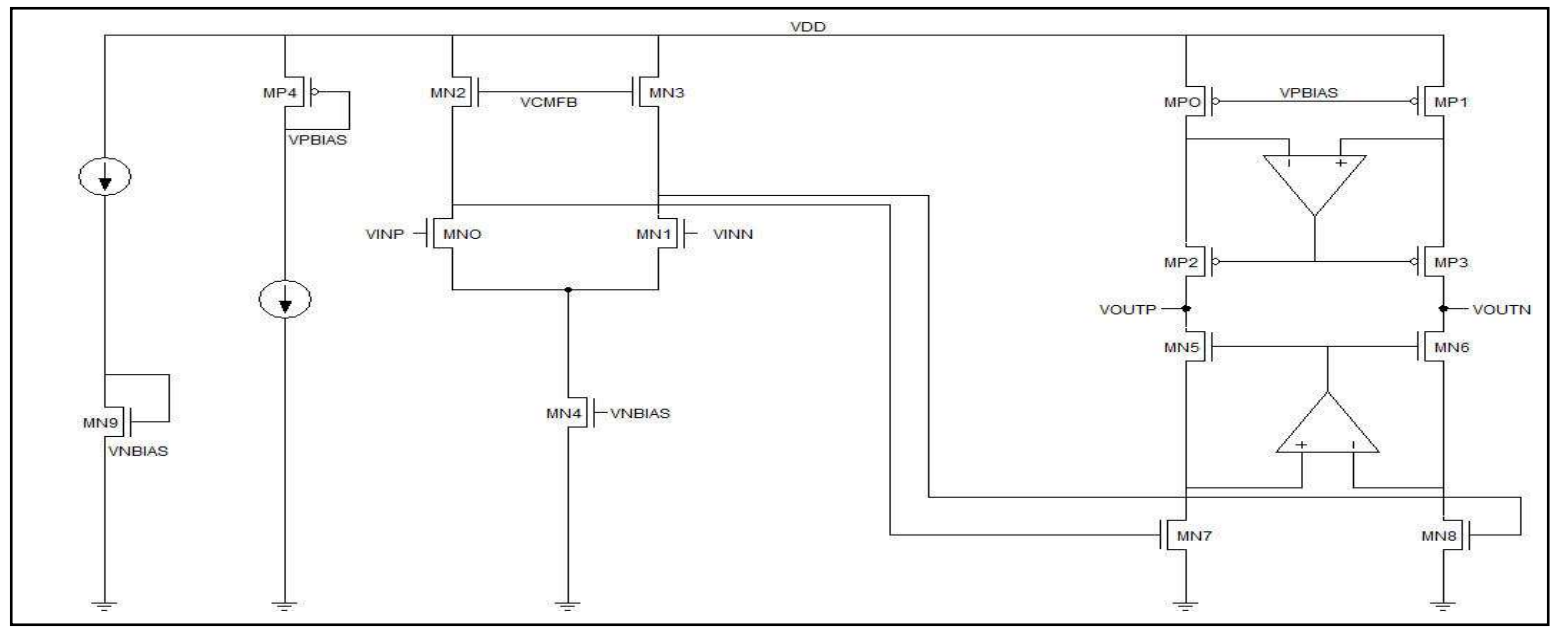

Fig. 3 Fully differential OTA

\subsubsection{Design of the op-amp:}

The op-amp is the most essential block in ADC[29-30]. The output impedance $\mathrm{R}_{\text {out }}$ is increased by the added gain stage A $_{\text {OTA }}$ as given in the following equation: 


$$
R_{\text {out }}=\left(g_{m 2} r_{02}\left(A_{\text {add }}+1\right)+1\right) r_{01}+r_{02}
$$

Further more ,the DC gain of the op-amp is improved in several orders of magnitude:

$$
\begin{gathered}
\left.A_{0, \text { tot }}=g_{m 1} r_{01}\left(g_{m 2} r_{02}\right)\left(A_{\text {new }}+1\right)+1\right) \\
=A_{\text {oTA }} g_{m 1} g m_{2} r_{o 1} r_{o 2}
\end{gathered}
$$

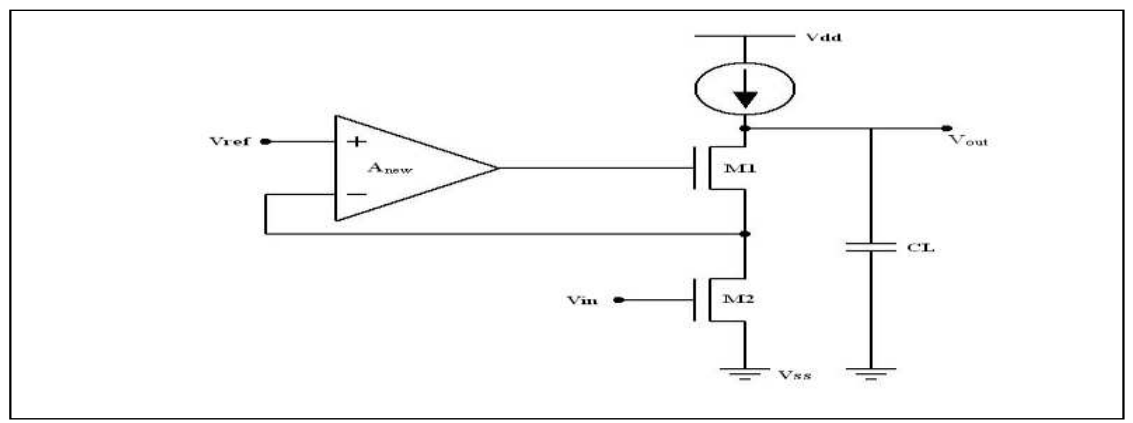

Fig. 4 Cascoded gain stage with gain boosting technique

To improve the voltage gain of the folded cascode amplifier the output impedance of the circuit need to be increased as shown in Fig.4. The design procedure starts with the design of fully differential op-amp and the second step is to introduce the gain boosting amplifier to obtain the desired gain without affecting the bandwidth of the op-amp. To start with, the sizing of the main differential input pair of the transistors $\mathrm{MN}_{0}, \mathrm{MN}_{1}$ is selected using the desired phase margin and the gain bandwidth specifications. This op-amp design includes the design of differential inputs, differential outputs, folded cascode bias circuits with common mode feedback (CMFB) and gain boosting amplifiers.[31-33]

The feedback factor $\beta$ is given by:

$$
\beta=\frac{C_{f}}{C_{1}+C_{p}+C_{f}}
$$

The unity gain frequency is given by:

$$
\omega_{\text {wnity }}=g_{m} \frac{C_{\bar{i}}+C_{p}+C_{f}}{C_{o}\left(C_{\bar{i}}+C_{p}+C_{f}+\left(C_{\bar{i}}+C_{p}\right) C_{f}\right.}
$$

The settling time $\tau$ can be found by:

$$
\tau=\left\{C_{p}+C_{i}+C_{o}+\frac{\left(C_{i}+C_{p}\right) C_{0}}{C_{f}}\right\} / g_{m}
$$

In Fig.5 the overdrive voltage of M10 is assigned high than that of input transistors M8 and M9 to boost the gain. The gain of this op-amp is mostly based upon the transistors M3, M5 and M8. The transistors M0 and M1 should be matched and kept wide enough to act as a resistor i.e. the overdrive voltage assigned is more compared to all. 


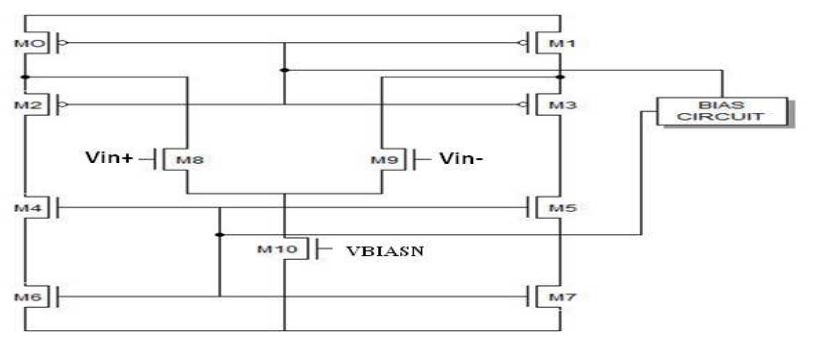

Fig. 5 P gain boost amplifier

The bias circuit is used in this op-amp is current biasing circuit which is current source with one Silicon based NMOS for n-bias and current source with one Silicon based PMOS for pbias. The current in the current source is scaled to give the bias voltage needed to make the circuit stable. Fig. 6 shows the $\mathrm{N}$ gain boost amplifier.

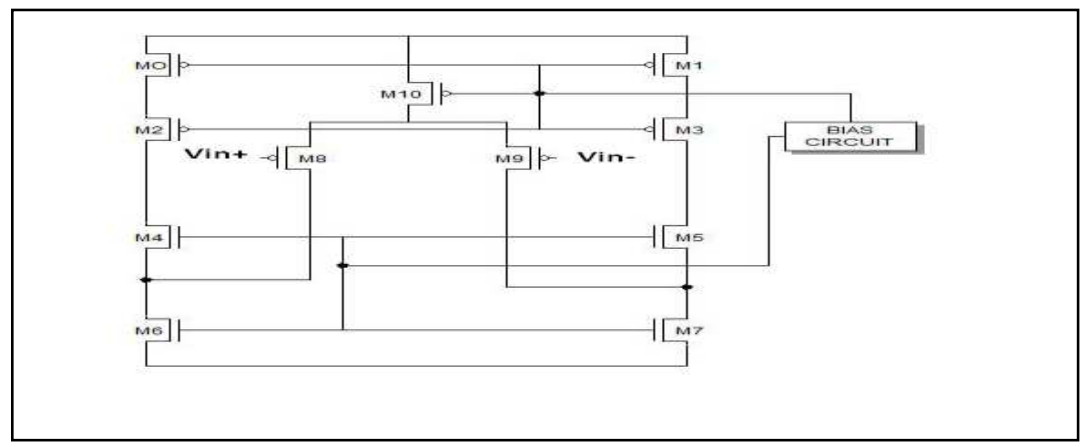

\subsubsection{Analysis of the op-amp}

Fig. $6 \mathrm{~N}$ gain boost amplifier

For the residue signal generated by the MDAC the op-amp loop-gain has to be at least $2^{9}$ $(54 \mathrm{~dB})$. In the design of the op-amp the main stage is the folded cascode op-amp which produces high gain.The $\mathrm{V}_{\mathrm{cm}}$ node is used to control the common mode bias voltage of the op-amp.Table 1 shows the performance summary of P Gain and N Gain Boost Amplifiers.

Table 1 Performance Summary of P Gain and N Gain Boost Amplifiers

\begin{tabular}{|l|c|c|}
\hline Specifications & $\begin{array}{c}\text { P Gain Boost } \\
\text { Amplifier }\end{array}$ & $\begin{array}{c}\text { N Gain Boost } \\
\text { Amplifier }\end{array}$ \\
\hline Supply Voltage (V) & 1.8 & 1.8 \\
\hline Input Voltage (V) & 0.5 & 0.5 \\
\hline Gain (dB) & 23.99 & 18.217 \\
\hline Phase Margin (Deg) & 72 & 73 \\
\hline Power Consumption (mW) & 0.7 & 0.7 \\
\hline
\end{tabular}


Simulation results show that the total DC gain of the op-amp is $86 \mathrm{~dB}$. Phase Margin value of the variable $g_{m}$ op-amp is greater than $80^{\circ}$. Table 2 shows the performance summary of variable $g_{m}$ op-amp.

Table 2 Performance summary of variable gm op-amp

\begin{tabular}{|l|c|}
\hline Specifications & $\begin{array}{c}\text { Variable } \mathbf{g m} \\
\text { Op-amp }\end{array}$ \\
\hline Supply Voltage (V) & 1.8 \\
\hline Input Voltage (V) & 0.5 \\
\hline Gain (main amplifier) & $45.03 \mathrm{~dB}$ \\
\hline Total Gain & $86 \mathrm{~dB}$ \\
\hline Gain Margin & $65.5 \mathrm{~dB}$ \\
\hline Phase Margin & $85-90^{0}$ \\
\hline Power Consumption (mW) & 1.64 \\
\hline Common Mode & $76.14 \mathrm{~dB}$ \\
\hline Rejection Ratio (dB) & $54.97 \mathrm{~dB}$ \\
\hline Power Supply Rejection Ratio (dB) & 230 \\
\hline GBW product (MHz) & 7.3 \\
\hline Unity Gain Frequency(MHz) & 486.3 \\
\hline Bandwidth(MHz) & $1.65 \mathrm{~V}$ \\
\hline Output swing & \\
\hline
\end{tabular}

\section{Simultaneous Capacitor sharing and Op-amp Sharing MDAC}

The capacitor $C_{1 \mathrm{f}}$ is composed into two parts: $C_{2 \mathrm{f}}$ and $\mathrm{C}_{2 \mathrm{~s}}$. During the phase $\Phi_{1}$, the analog input signal is sampled on the two capacitors $\mathrm{C}_{1 \mathrm{f}}$ and $\mathrm{C}_{1 \mathrm{~s}}$. The residue signal is generated from each stage during the phase $\Phi_{2}$ and the residue signal is not provided to the sampling capacitors in the second stage of the pipelined ADC.The residue signal is detained on $\mathrm{C}_{1 \mathrm{f}}$ which is the feedback capacitor.Using the stored value on the capacitor $\mathrm{C}_{1 \mathrm{f}}$, residue signal is produced. This stored value is provided to the sampling capacitors of the third stage $\mathrm{C}_{3 \mathrm{f}}$ and $\mathrm{C}_{3 \mathrm{~s}}$ during the next phase $\Phi_{1}$. When the second stage is generating its residue signal, the next input signal need to be sampled are used[34-36]. The feedback capacitors named as $\mathrm{C}_{1 \mathrm{fe}}$ and $\mathrm{C}_{1 \mathrm{fo}}$ are used.The matching network is used in the initial stage of ADC. In the proposed pipelined ADC the simultaneous capacitor sharing and op-amp sharing technique is used .Fig. 7 shows the simultaneous capacitor and op-amp sharing technique. 


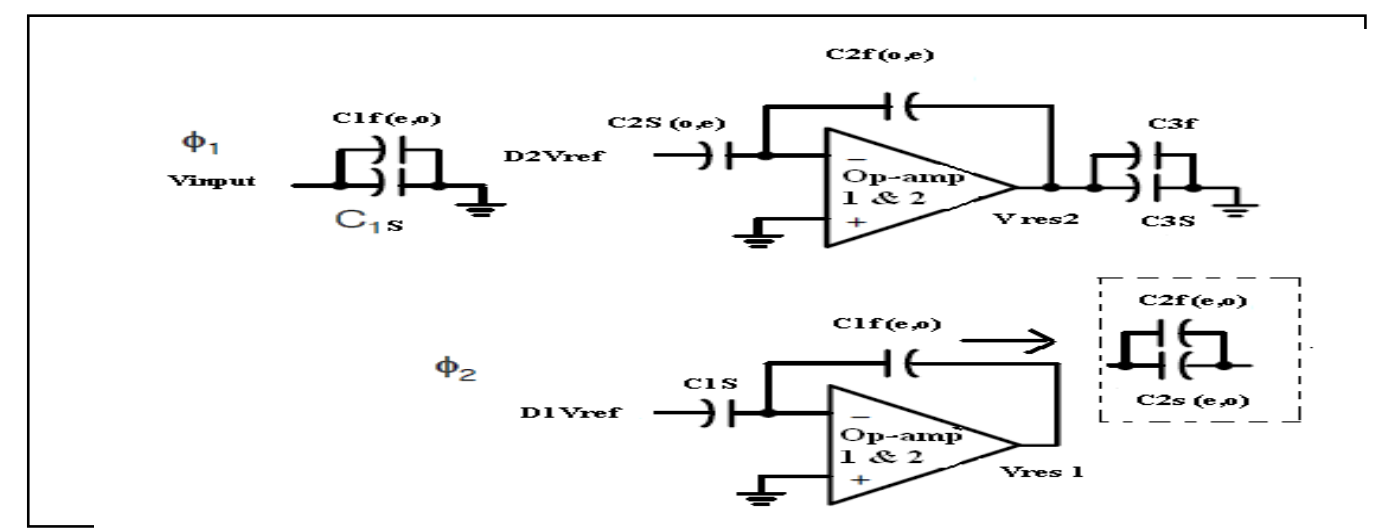

Fig.7 Simultaneous capacitor and op-amp sharing technique

\subsubsection{Sampling Network for Stage1}

The use of $\mathrm{S} / \mathrm{H}$ circuit is avoided with the MDAC and the sub-ADC performing the sampling procedure [37]. In this work, the aperture error is minimized by matching the sampling network through cautious design of the aspect ratio (W/L) of the transistor. The gate source voltage $\left(V_{\mathrm{gs}}\right)$ is same for the sampling capacitance $\mathrm{C}_{\mathrm{s}}$ and $\mathrm{C}_{\text {com1 }}-\mathrm{C}_{\text {com4 }}$ in the sampling network.This is because the above mentioned sampling capacitance is connected to the same common mode voltage. Fig.8 shows the proposed sampling network for the initial stage. Fig.9 shows the timing diagram for the sampling network.

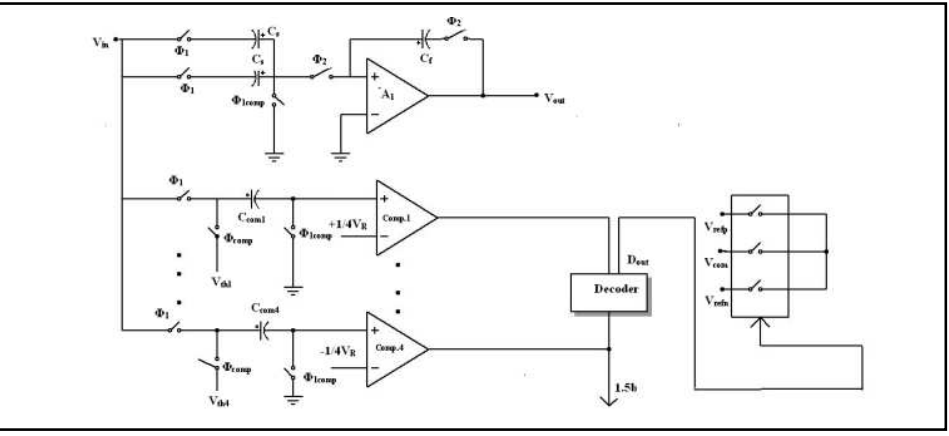

Fig. 8 Proposed sampling network for the first stage

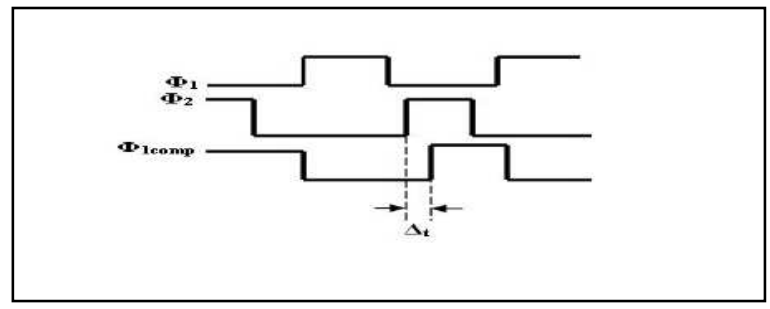

Fig. 9 Timing Diagram for the sampling network 


\section{$4 \quad$ Results and Discussion}

The SHA-less Pipelined ADC is simulated in a 180nm Silicon based CMOS process. Various sub circuits like dynamic comparator, op-amp, MDAC, Sub ADC and sub DAC was integrated for pipelined ADC[38-39]. Fig.10 shows the 1024 points FFT spectrum with the input frequency of $2 \mathrm{MHz}$.

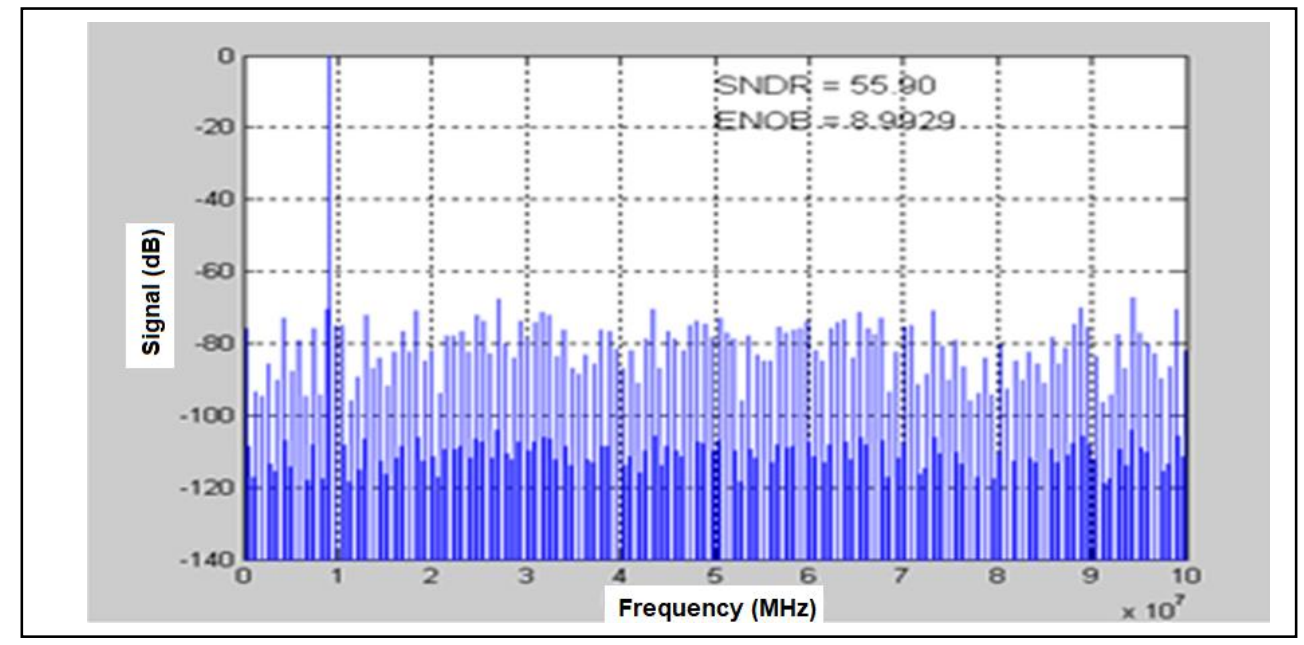

Fig.10 Obtained FFT spectrum of pipelined ADC

Fig. 11 shows the layout of 10-bit SHA less pipelined ADC.The delay and the power consumption obtained after post layout simulation is $15.1 \mathrm{~ns}$ and $15 \mathrm{~mW}$. C.

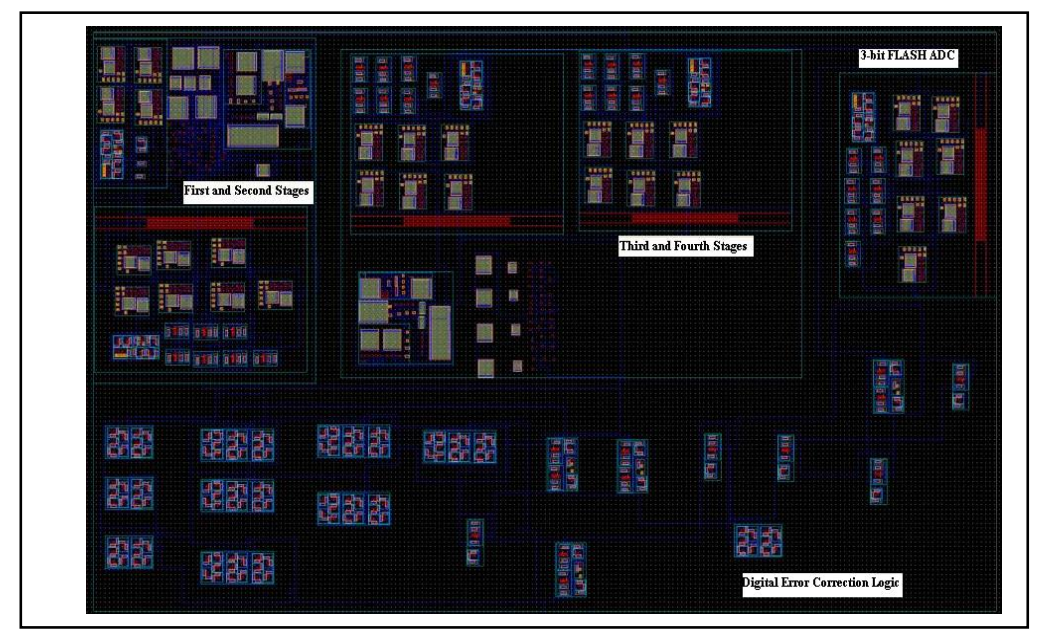

Fig. 11 The layout of the 10-bit SHA less Pipelined ADC

Table 3 shows the Performance summary of 10-bit SHA less pipelined ADC. The10-bit SHA less pipelined ADC was designed in a $180 \mathrm{~nm}$ Silicon based CMOS process and achieves $56.12 \mathrm{~dB}$ SNDR,56 dB SNR,70 dB SFDR, from a 1.8V supply voltage. 
Table 3 Performance Summary of 10-bit SHA less Pipelined ADC

\begin{tabular}{|c|c|}
\hline Technology & $180 \mathrm{~nm}$ \\
\hline Resolution & $10 \mathrm{bit}$ \\
\hline Input Range & $1 \mathrm{~V}_{\mathrm{p}-\mathrm{p}}$ \\
\hline Frequency Range( $\left.\mathrm{f}_{\mathrm{in}}\right)$ & $2 \mathrm{MHz}$ \\
\hline Sampling frequency $\left(\mathrm{f}_{\mathrm{s}}\right)$ & $40 \mathrm{MHz}$ \\
\hline DNL & $+0.57 /-1 \mathrm{LSB}$ \\
\hline INL & $+0.74 /-0.74 \mathrm{LSB}$ \\
\hline SFDR & $70 \mathrm{~dB}$ \\
\hline SNDR & $56.12 \mathrm{~dB}$ \\
\hline ENOB & $9.0289 \mathrm{bits}$ \\
\hline FOM & $0.35 \mathrm{pJ} / \mathrm{step}$ \\
\hline Total Power & $7.3 \mathrm{~mW}$ \\
\hline Conversion time & $2.5 \mathrm{~ns}$ \\
\hline Area & $0.63 \mathrm{~mm}$ \\
\hline
\end{tabular}

Table 4 Comparison of the SHA-less pipelined ADC with some reported pipelined ADCs.

\begin{tabular}{|c|c|c|c|c|c|c|c|c|c|c|}
\hline$\frac{8}{0}$ & 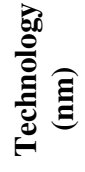 & 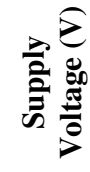 & 总 & 总 & $\stackrel{\Xi}{0}$ & 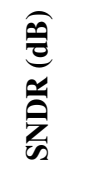 & 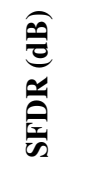 & $\sum_{\text {¿ }}^{\infty}$ & 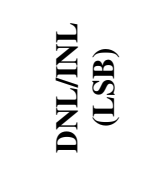 & 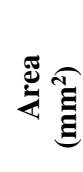 \\
\hline [10] & 180 & 1.8 & 40 & 10 & 23.4 & 59.53 & 71.67 & 9.40 & $\begin{array}{c}0.28 / 0.32 / \\
0.62\end{array}$ & 0.63 \\
\hline [12] & 180 & 1.8 & 30 & 10 & 21.6 & 57.41 & 65.93 & 9.10 & $0.57 / 0.8$ & 0.70 \\
\hline [30] & 180 & $1.8 / 3$ & 80 & 10 & 69.0 & - & 72.78 & 9.29 & $\begin{array}{c}+0.2 /-0.25 \\
+0.5 /-0.5\end{array}$ & 1.85 \\
\hline$[31$ & 180 & 1.8 & 50 & 10 & 12.0 & 56.20 & 72.70 & 9.03 & $0.39 / 0.81$ & 0.86 \\
\hline [32] & 180 & 1.8 & 30 & 10 & 21.6 & 58.50 & 66.10 & - & $0.3 / 0.46$ & 1.85 \\
\hline [36] & 180 & 1.8 & 200 & 10 & 56 & 61.07 & - & 9.85 & - & 1.44 \\
\hline $\begin{array}{c}\text { Present } \\
\text { work }\end{array}$ & 180 & 1.8 & 40 & 10 & 7.30 & 56.10 & 70.00 & 9.02 & $\begin{array}{l}+0.57 /-1 / \\
+0.7 /-0.74\end{array}$ & 0.35 \\
\hline
\end{tabular}


Table 4 shows the comparison of the 10-bit SHA-less pipelined ADC with some reported pipelined ADCs. Comparing the present work with the reported work at [27] 39.1\% of power reduction has been achieved. When compared to the other pipelined ADCs reported in previous reported works this 10-bit SHA less Pipelined ADC has less power consumption.

\section{CONCLUSION}

A 40MSPS pipelined ADC which is suitable for low power has been described. By removing the front-end SHA, considerable power saving is obtained. The variable $\mathrm{g}_{\mathrm{m}}$ operational transconductance amplifier used in the design has been designed with a gain of $45 \mathrm{~dB}$.Clocked dynamic comparator is also designed and the same is used to build sub-ADC's which generates the LSB and MSB of the each single stage.Simulation results of the pipelined ADC in a 180nm Silicon based CMOS process shows an SFDR of $70 \mathrm{~dB}$, SNDR of $56.12 \mathrm{~dB}$, ENOB of 9.02 bits and FOM of $0.35 \mathrm{pJ} / \mathrm{step}$ while consuming only $7.3 \mathrm{~mW}$ for a $2 \mathrm{MHz}$ input signal.From the results it was shown that the designed ADC maintains a good dynamic performance and low power consumption suitable for SOC Digital TV Application.

\section{ETHICS APPROVAL AND CONSENT TO PARTICIPATE Yes CONSENT FOR PUBLICATION}

Consent to Publish Form The Author transfers to Springer (respective to owner if other than Springer and for U.S. government employees: to the extent transferable) the non-exclusive publication rights and he warrants that his/her contribution is original and that he/she has full power to make this grant. The author signs for and accepts responsibility for releasing this material on behalf of any and all co-authors. This transfer of publication rights covers the non-exclusive right to reproduce and distribute the article, including reprints, translations, photographic reproductions, microform, electronic form (offline, online) or any other reproductions of similar nature. The author may self-archive an author-created version of his article on his own website and his institution's repository, including his final version; however he may not use Springer's PDF version which is posted on www.springerlink.com. Furthermore, the author may only post his version provided acknowledgement is given to the Journal and Springer as one of the original places of publication and a link is inserted to the published article on Springer's website. Please use the appropriate DOI for the article (go to the Linking Options in the article, then to OpenURL and use the link with the DOI). Articles disseminated via www.springerlink.com are indexed, abstracted, and referenced by many abstracting and information services, bibliographic networks, subscription agencies, library networks, and consortia. After submission of this agreement signed by the corresponding author, changes of authorship or in the order of the authors listed will not be accepted by Springer. Title : A novel architecture for 10-bit 40MSPS low power Pipelined ADC using simultaneous capacitor and op-amp sharing technique

Author(s): D.S.Shylu ${ }^{1}$ D.Jackuline Moni ${ }^{2}$ P.Sam Paul ${ }^{3}$ D.Nirmal ${ }^{4}$ Author's signature:

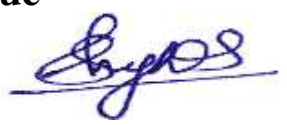
Date:16.4.2021 


\section{AVAILABILITY OF DATA AND MATERIALS}

Yes

\section{COMPETING INTERESTS}

The intent of the policy is not to prevent authors with a potential conflict of interest from publication. It is merely intended that any potential conflict should be identified openly so that the readers may form their own judgments about the article with the full disclosure of the facts. It is for the readers to determine whether the authors' outside interest may reflect a possible bias in either the exposition or the conclusions presented. The corresponding author will complete and submit this form on behalf of all authors listed below. Article Title A novel architecture for 10-bit 40MSPS low power Pipelined ADC using simultaneous capacitor and op-amp sharing technique Authors: D.S.Shylu ${ }^{1}$ D.Jackuline Moni $^{2}$ P.Sam Paul $^{3}$ D.Nirmal ${ }^{4}$ MS Id. No. .........Please note that a conflict of interest statement is published with each paper. I hereby certify that, to the best of my knowledge: 1 No financial support or benefits have been received by me, by any member of my immediate family, or any individual or entity with whom or with which I have a significant relationship from any commercial source which is related directly or indirectly to the scientific work which is reported on in the article except as described below. (I understand an example of such support would be a consulting fee, support for research activities or a gift.) 2 Moreover, neither I, nor any member of my immediate family, nor any individual or entity with whom or with which I have a significant relationship has a financial interest in the subject matter discussed in the manuscript. (I understand an example of such a financial interest would be a stock interest in any business entity which is included in the subject matter of the manuscript or which sells a product relating to the subject matter of the manuscript.) Exceptions to points 1 and/or 2: Please describe here, using a separate sheet if necessary, any financial interests/arrangements with one or more organizations that could be perceived as a real or apparent conflict of interest in the context of the subject of your manuscript:A novel architecture for 10-bit 40MSPS low power Pipelined ADC using simultaneous capacitor and op-amp sharing technique Name D.S.Shylu ${ }^{1}$

D.Jackuline Moni² P.Sam Paul ${ }^{3}$ D.Nirmal ${ }^{4}$ Signature

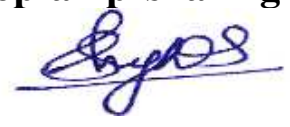

Date 16.4.2021

\section{FUNDING}

The research support was provided by Karunya Institute of Technology \& Sciences,Karunya Nagar, Coimbatore.

\section{AUTHORS' CONTRIBUTIONS}

All authors whose names appear on the submission

1) made substantial contributions to the conception or design of the work

2) drafted the work or revised it critically for important intellectual content

3) approved the version to be published

4) agree to be accountable for all aspects of the work in ensuring that questions related to the accuracy or integrity of any part of the work are appropriately investigated and resolved.

\section{ACKNOWLEDGEMENTS}

The authors are thankful to the administration of Karunya Institute of Technology and Sciences and VLSI Lab of the Department of ECE. School of Engineering \&Technology, KITS for facilitating this research work. 


\section{* AUTHORS' INFORMATION (OPTIONAL)}

D.S.Shylu' Associate Professor, Department of Electronics \& Communication Engineering, Karunya Institute of Technology and Sciences, Coimbatore, 641114, Tamil Nadu, India.Phone:9487224478,email: mail2shylu@yahoo.com

D.Jackuline Moni, Professor,Professor, Karunya Institute of Technology and Sciences, Coimbatore, 641114, Tamil Nadu, India.Phone:9443577599,email: moni@karunya.edu

P.Sam Paul,Professor, Department of Mechanical Engineering, Karunya Institute of Technology and Sciences, Coimbatore, 641114, Tamil Nadu, India.Phone:9443496082 E-mail: psam_paul@rediffmail.com.

D.Nirmal,Associate Professor, Department of Electronics \& Communication Engineering, Karunya Institute of Technology and Sciences, Coimbatore, 641114, Tamil Nadu, India.Phone:9789498810, e-mail: nirmal@karunya.edu

\section{PLEASE INCLUDE THE SUB-SECTIONS BELOW OF COMPLIANCE WITH ETHICAL STANDARDS SECTION}

All the sources are included

\section{a. DISCLOSURE OF POTENTIAL CONFLICTS OF INTEREST Not Applicable}

Disclosure of potential conflicts of interests Authors must disclose all relationships or interests that could have direct or potential influence or impart bias on the work. Although an author may not feel there is any conflict, disclosure of relationships and interests provides a more complete and transparent process, leading to an accurate and objective assessment of the work. Awareness of a real or perceived conflicts of interest is a perspective to which the readers are entitled. This is not meant to imply that a financial relationship with an organization that sponsored the research or compensation received for consultancy work is inappropriate. Examples of potential conflicts of interests that are directly or indirectly related to the research may include but are not limited to the following: - Research grants from funding agencies (please give the research funder and the grant number) $\bullet$ Honoraria for speaking at symposia $\bullet$ Financial support for attending symposia $\bullet$ Financial support for educational programs $\bullet$ Employment or consultation $\bullet$ Support from a project sponsor $\bullet$ Position on advisory board or board of directors or other type of management relationships $\bullet$ Multiple affiliations - Financial relationships, for example equity ownership or investment interest - Intellectual property rights (e.g. patents, copyrights and royalties from such rights) • Holdings of spouse and/or children that may have financial interest in the work In addition, interests that go beyond financial interests and compensation (non-financial interests) that may be important to readers should be disclosed. These may include but are not limited to personal relationships or competing interests directly or indirectly tied to this research, or professional interests or personal beliefs that may influence your research. The corresponding author collects the conflict of interest disclosure forms from all authors. In author collaborations where formal agreements for 
representation allow it, it is sufficient for the corresponding author to sign the disclosure form on behalf of all authors. Examples of forms can be found here: https://www.springer.com/?SGWID=0-102-2-1469445preview\&dynamic=true The corresponding author will include a summary statement in the text of the manuscript in a separate section before the reference list, that reflects what is recorded in the potential conflict of interest disclosure form(s). See below examples of disclosures: Funding: This study was funded by X (grant number X)

Not Applicable

\section{b. RESEARCH INVOLVING HUMAN PARTICIPANTS AND/OR ANIMALS Not Applicable c. INFORMED CONSENT Not Applicable}

All individuals have individual rights that are not to be infringed. Individual participants in studies have, for example, the right to decide what happens to the (identifiable) personal data gathered, to what they have said during a study or an interview, as well as to any photograph that was taken. Hence it is important that all participants gave their informed consent in writing prior to inclusion in the study. Identifying details (names, dates of birth, identity numbers and other information) of the participants that were studied should not be published in written descriptions, photographs, and genetic profiles unless the information is essential for scientific purposes and the participant (or parent or guardian if the participant is incapable) gave written informed consent for publication. Complete anonymity is difficult to achieve in some cases, and informed consent should be obtained if there is any doubt. For example, masking the eye region in photographs of participants is inadequate protection of anonymity. If identifying characteristics are altered to protect anonymity, such as in genetic profiles, authors should provide assurance that alterations do not distort scientific meaning. The following statement should be included:Informed consent: "Informed consent was obtained from all individual participants included in the study." If identifying information about participants is available in the chapter, the following statement should be included: "Additional informed consent was obtained from all individual participants for whom identifying information is included in this chapter.

\section{References}

1. Byung-Geun Lee, Robin M. Tsang. (2009). "A 10-bit 50 MS/s Pipelined ADC With Capacitor-Sharing and Variable-gm_ Op-amp", IEEE Trans.Circuits Syst.Vol.44,No.3, pp.883-890.

2. Crols J., Steyaert M.,Switched-op-amp, 942 (1994). "An approach to realize full CMOS switched-capacitor circuits at very low power supply voltages", IEEE J. Solid-State Circuits,Vol.29,No.8, pp.936.

3. Cho T.B., Gray P. R., "A 10 b, 20 M sample/s, 35mWpipeline A/D converter, (1995)",IEEE J. Solid-State Circuits, 30, pp.166-172.

4. Cline D., Gray P.,(1996) "A power optimized 13-b 5Msamples/s pipelined analogto-digitalconverter in $1.2 \mu \mathrm{m} \mathrm{CMOS",IEEE} \mathrm{J.} \mathrm{Solid-State} \mathrm{Circuits,} \mathrm{Vol.31,No.3,}$ pp.294-303. 
5. Chiaburu L., (2003) "A Method to Reduce Power Consumption in Pipelined A/D Converters",IEEE conference, pp.I-854- I-848.

6. Chang D. Y., (2003) "Design techniques for a pipelined ADC without using a frontend sample-and-hold amplifier", IEEE Trans. Circuits Syst. I, Reg. Papers, Vol.51,No.11, pp.2123-2132.

7. Dongre,Yeshhwantrao Chavan,Akre,Kamdi,Sarangam,(2014) "A 10-bit 25MSPS low power pipeline ADC for Mobile HDTV Receiver System", Int. Conference (ICECS)1-6.

8. Dong HuanZhi, Zhang YingQin, (2012)"A 10b 20MS/s Low Power Pipelined A/D Converter Without Dedicated SHA",Physics Procedia,33, pp.1366 - 1373.

9. Francke, Johannes, Yang, Hua-zhong Z, Luo, Rong,(2006) "A 10-Bit, 40 MSamples/s Low Power Pipeline ADC for System-on-a-Chip Digital TV Application",International Semiconductor Conference, pp.421-424.

10. Ghil-Geun Oh, Chang-Kyo Lee, and Seung-Tak Ryu,(2014) "A 10-Bit 40-MS/s Pipelined ADCWith a Wide Range Operating Temperature for WAVE Applications",IEEE Trans.Circuits Syst., Vol.61,No.1, pp.6-10.

11. Imran Ahmed, Mulder, and David A. Johns, C ,2010) "A Low-Power Capacitive Charge Pump Based Pipelined ADC",IEEE Journal of Solid State Circuits,45(5), pp.1016-1027.

12. Jian Li, Xiaoyang Zeng, Lei Xie, Jun Chen, Jianyun Zhang and Yawei Guo, (2006),"A 1.8-V 22-mW 10-bit 30-MS/s Subsampling Pipelined CMOS ADC",IEEE Custom Integrated Circuits Conference (CICC), pp.513-516.

13. Jeon Y. D., Lee S. C., Kim K. D.,. Kwon J. K, and Kim J., (2007) "A 4.7 mW 0.32 $\mathrm{mm} 10 \mathrm{~b} 30 \mathrm{MS} / \mathrm{s}$ pipelined ADC without a front-end S/H in $90 \mathrm{~nm} "$, CMOS,ISSCC Dig. Tech. Papers, pp.456-459 .

14. Krishnaswamy Nagaraj, Fetterman H.S., Anidjar J., Lewis S.H., Renninger R.G.,(1997) "A 250-mW, 8-b, 52-Msamples/s Parallel-Pipelined A/D Converter with Reduced Number of amplifiers",IEEE J. Solid-state circuits, 32, pp.312-320.

15. Kim H. C., Kim D. K. J.,(2006), "A partially switched-op-amp technique forhighspeed low-power pipelined analog-to-digital converters", IEEETrans. Circuits Syst. I, Reg. Papers, Vol.53,No.4, pp.795-801.

16. Li Su, Yu-lin Qiu,(2005)"Design of a Fully Differential Gain-Boosted Folded- Cascode Op Amp with Settling Performance Optimization",IEEE Conference,441- 444.

17. Zhao Xiaoxiao1, Li Fule1, Bin Wu., 2011,(2005), "A SHA-less 12-bit 200-MS/s Pipeline ADC.ASID, pp.161-164.

18. Mehr, Singer L.(2000), "A 55-mW 10-bit 40-Msample/s Nyquist-rate CMOS ADC",IEEE Journal of Solid-State Circuits, 35, pp.318-325.

19. Min B.M., Kim P., Bowman F. W., Boisvert D. M.,. Aude A. J.(2003), " A 69-mW 10-bit 80-MSample/s pipelined CMOS ADC", IEEE J. Solid-State Circuits, Vol.38,No.12, pp.2031-2039. 
20. Malik S., Geiger R.,(2005), "Simultaneous capacitor sharing and scaling for reduced power in pipeline ADCs", Proc. IEEE MWSCAS,2,1015-1018.

21. Nairn D., (2000),"A 10-bit, 3 V, 100 MS/s pipelined ADC",Proc. IEEE Custom Integrated Circuits Conf., pp.257-260.

22. Sasidhar, N.,(2009),"A Low Power pipelined ADC Using Capacitor and op-amp sharing Technique With a Scheme to Cancel the Effect of Signal Dependent Kickback", IEEE journal of solid-state circuits, Vol.44,No.9, pp.2392-2401.

23. N. Sasidhar, Y. Kook, S. Takeuchi, K. Hamashita, K. Takasuka, P. Hanumolu, and

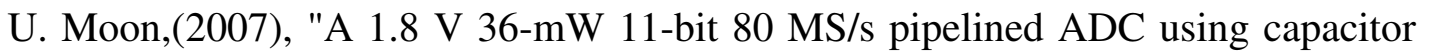
and op-amp sharing", IEEE Asian Solid-State Circuits Conf.,ASSCC'07, pp.240243.

24. Waltari M. , Halonen K. A. I., "1-V 9-Bit pipelined switched-op-amp ADC,(2001)," IEEE J. Solid-State Circuits, 36(1), pp.129-134.

25. Xiaoke Wen, Rui Wang, Renguo Peng, Min Hao, Jinghong Chen.(2012), "A 12b 60MS/s SHA-Less Op-amp-Sharing Pipeline A/D with Switch-Embedded Dual Input OTAs",ICMPBE, pp.1875-3892.

26. Yoo S., Park J., Yang H., Bae H., Moon K., Park H., Lee S., and Kim J.(2003), "A 10 b $150 \mathrm{MS} / \mathrm{s} 123 \mathrm{~mW} 0.18 \mathrm{~m}$ CMOS pipelined ADC",in IEEE Int. Solid-State Circuits Conf. Dig. Tech. Papers, pp.326-327.

27. Yoshioka M., Kudo M., Gotoh K., Watanabe Y.(2005),"A 10b 125 MS/s 40 mW

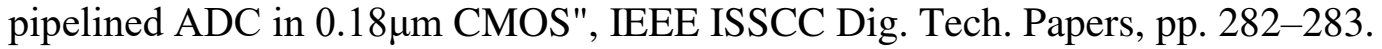

28. Byung-Moo Min,Kim P.,Bowman F.W.,Boisvert D.M.,Aude A.J(2003)., "A 69mW 10-bit 80-MSample/s Pipelined CMOS ADC, IEEE Journal of Solid-State Circuits,Vol. 38(12),2031 - 2039.

29. Byung and Robin M. Tsang (2009) "A 10-bit 50 MS/s pipelined ADC with capacitor-sharing and variable- op-amp", IEEE Transaction on Circuits and Systems II 88(3), 883-890.

30. Chang D. Y. (2007) "Design techniques for a pipelined ADC without using a frontend sample-and-hold amplifier", IEEE Transaction on Circuits and Systems I, Reg. Papers, 51(11), 2123-2132.

31. Shylu D.S.,Jackuline Moni D. and Renita Pearlin T. (2016) "A 10-bit 40MS/s low power SHA-less pipelined ADC for System -On-Chip Digital TV Application”, ICDCS,305-309.

32. Hafiz M.Obaid,Shabbir Majeed Chaudhry (2015), “ Design of a Linear High-Drive Class-AB Differential Amplifier in 90nm CMOS Technology,National Academy Science Letters, Vol.38(6),pp.489-492.

33. Umair Munir Minhas,Farhat Abbas (2018), “ A High Gain Bulk Driven Operational Transconductance Amplifier (OTA) for Wireless Body Area Networks, National Academy Science Letters, Vol.41(1),pp.41-45. 
34. Shan-Hao Sung; Jonathan Hsia; Chih-Ping Yu (2018), "A 10-bit 200-MS/s switched-current pipelined ADC for analog front end of XDSL, 7th International Symposium on Next Generation Electronics (ISNE), Taipei, Taiwan.

37. Shylu D.S.,Jackuline Moni D.,Nivetha G.(2016) "Design and Power Optimization of High-Speed Pipelined ADC with Programmable Gain Amplifier for Wireless Receiver Applications", Wireless Personal Communication, Springer,90,657-678.

38. Shylu D.S., Jackuline Moni D., (2016),"Design of low power dynamic comparator with reduced kick back noise using clocked PMOS technique", Journal of Electrical Engineering (JEE), 16(3),1-10.

39. Shylu D.S.,Jackuline Moni D. (2014) “A 1.8V 22mW 10 bit 165 MSPS Pipelined ADC for Video Applications", WSEAS Transactions on Circuits and systems, 13, 343-355. 
Figures

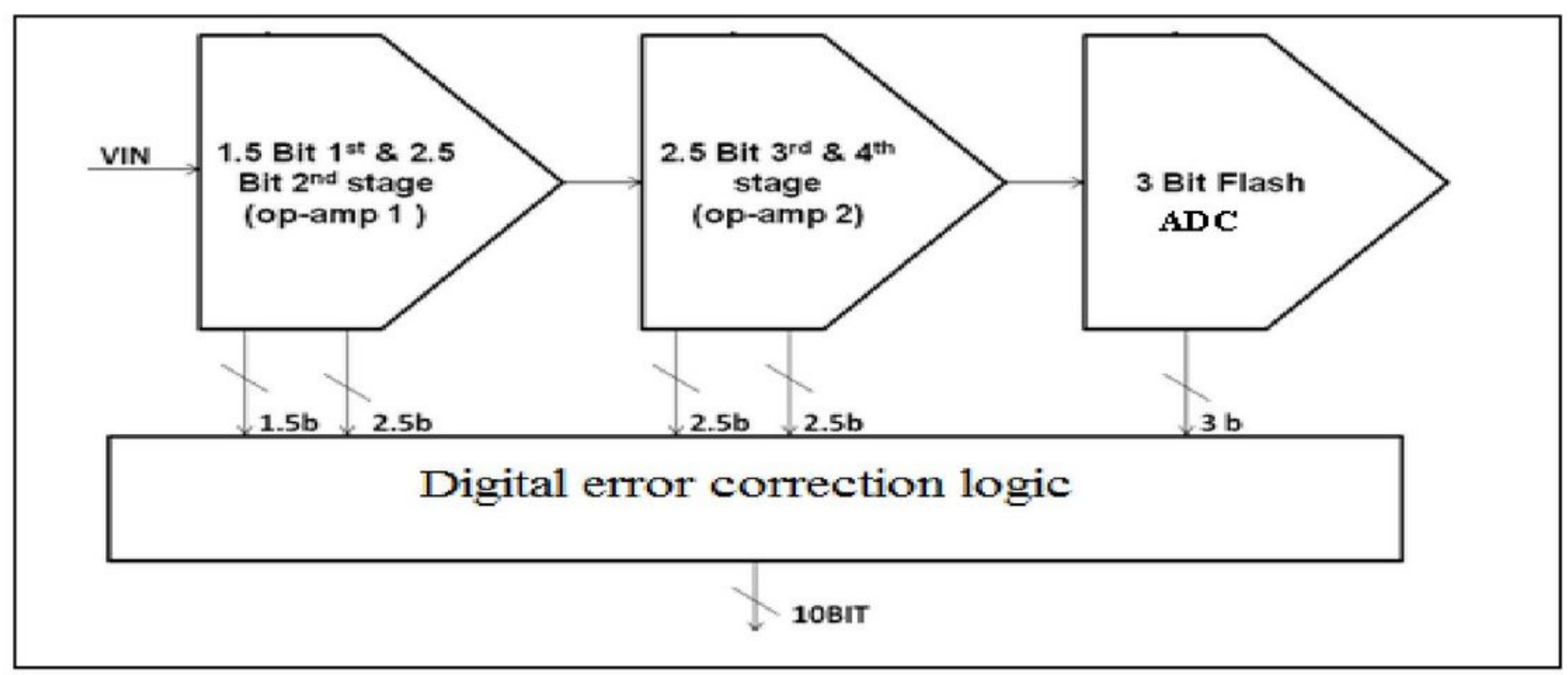

Figure 1

A 10-bit SHA-less Pipelined ADC structure

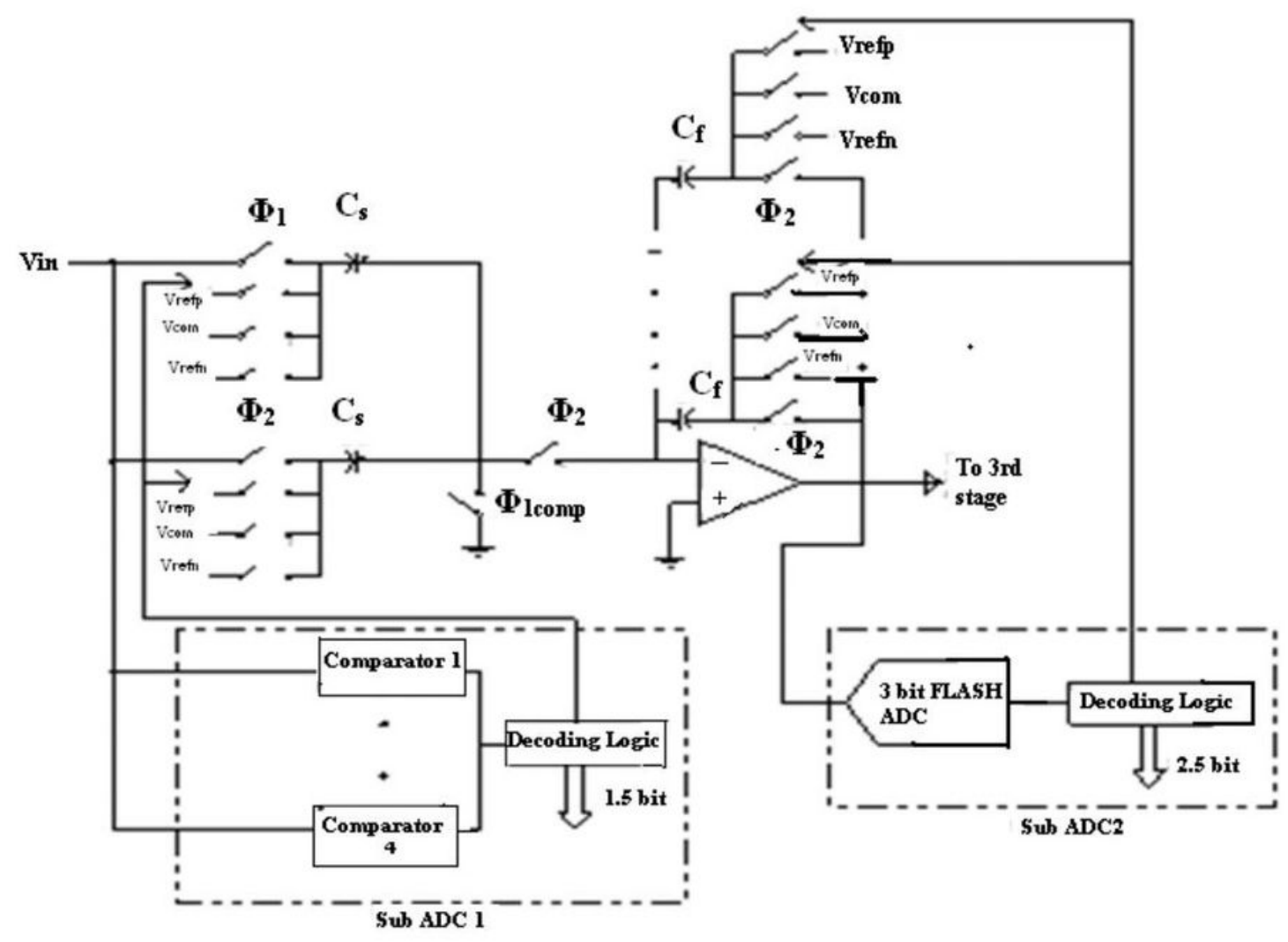


Figure 2

First and second stages of 10-bit Pipelined ADC

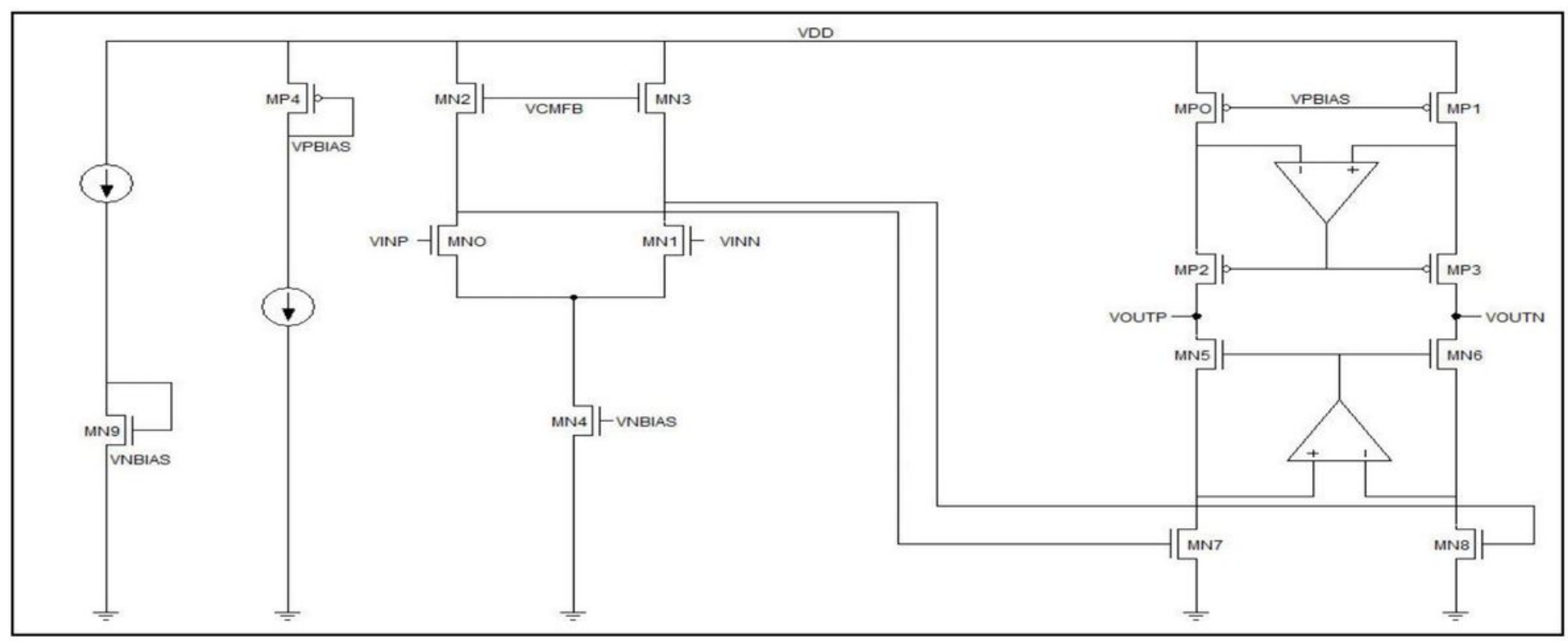

Figure 3

Fully differential OTA

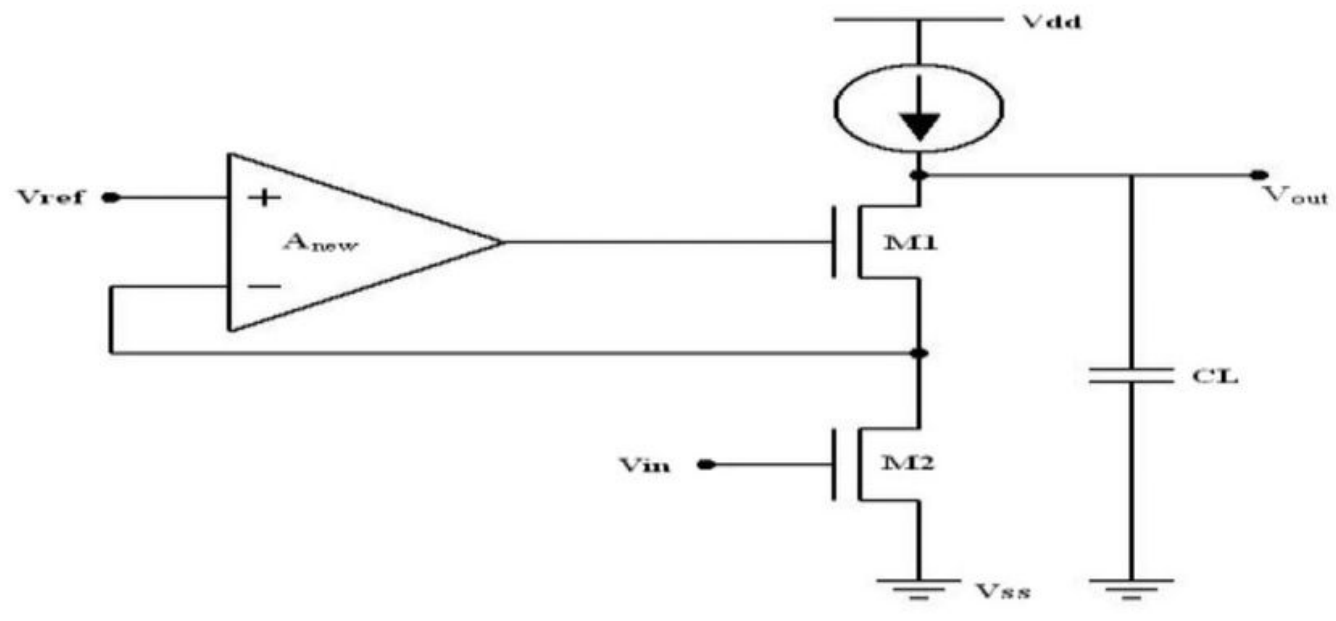

Figure 4

Cascoded gain stage with gain boosting technique 


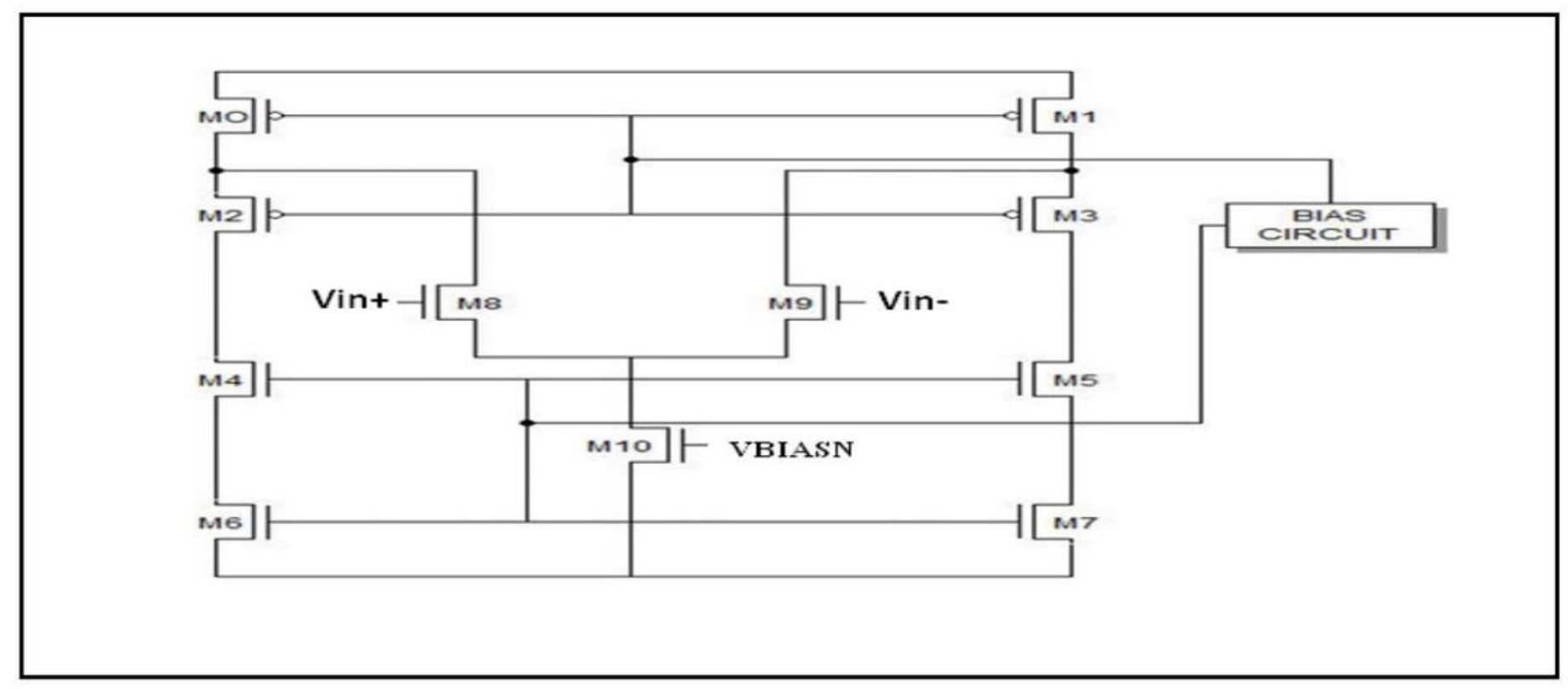

Figure 5

$P$ gain boost amplifier

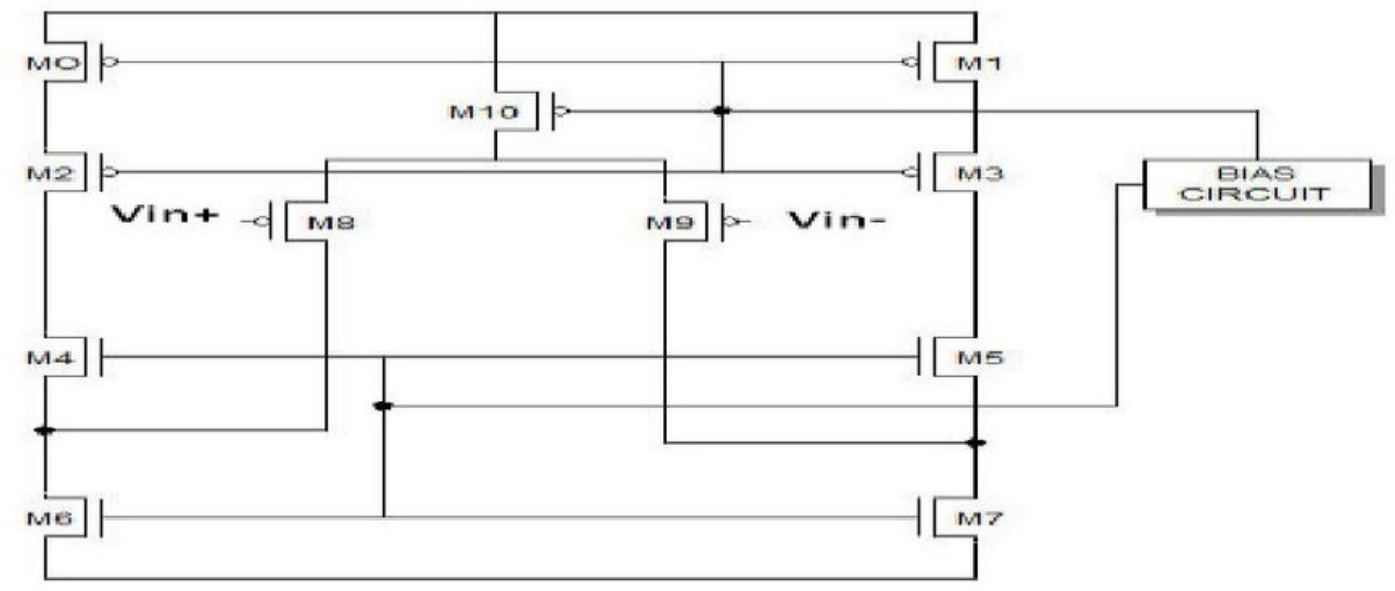

Figure 6

$\mathrm{N}$ gain boost amplifier 


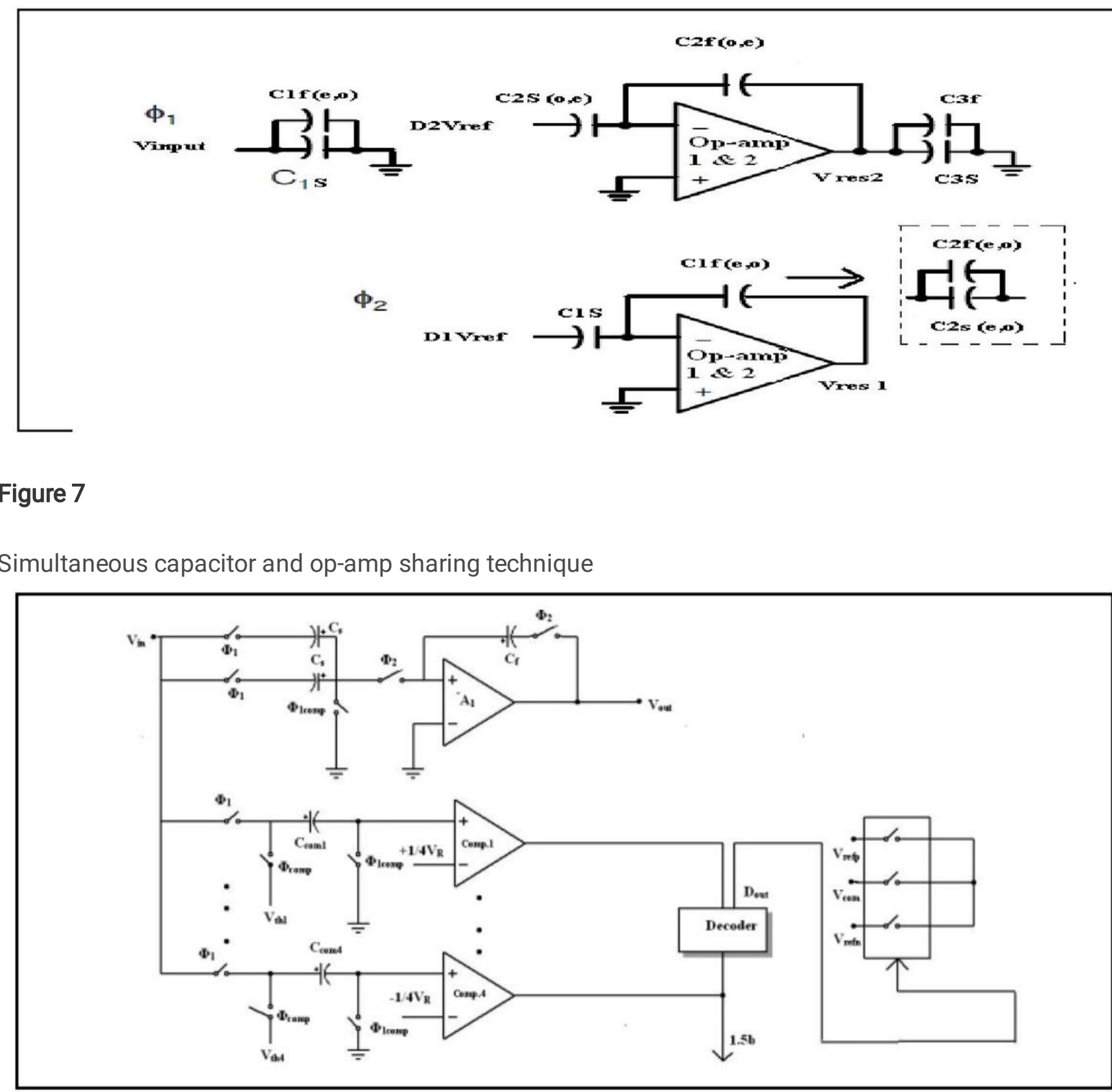

Figure 8

Proposed sampling network for the first stage 


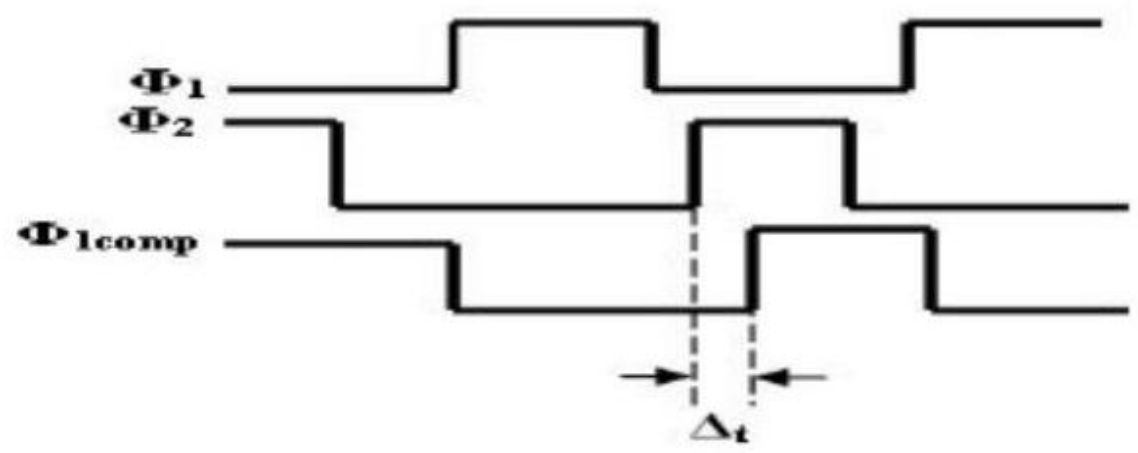

Figure 9

Timing Diagram for the sampling network

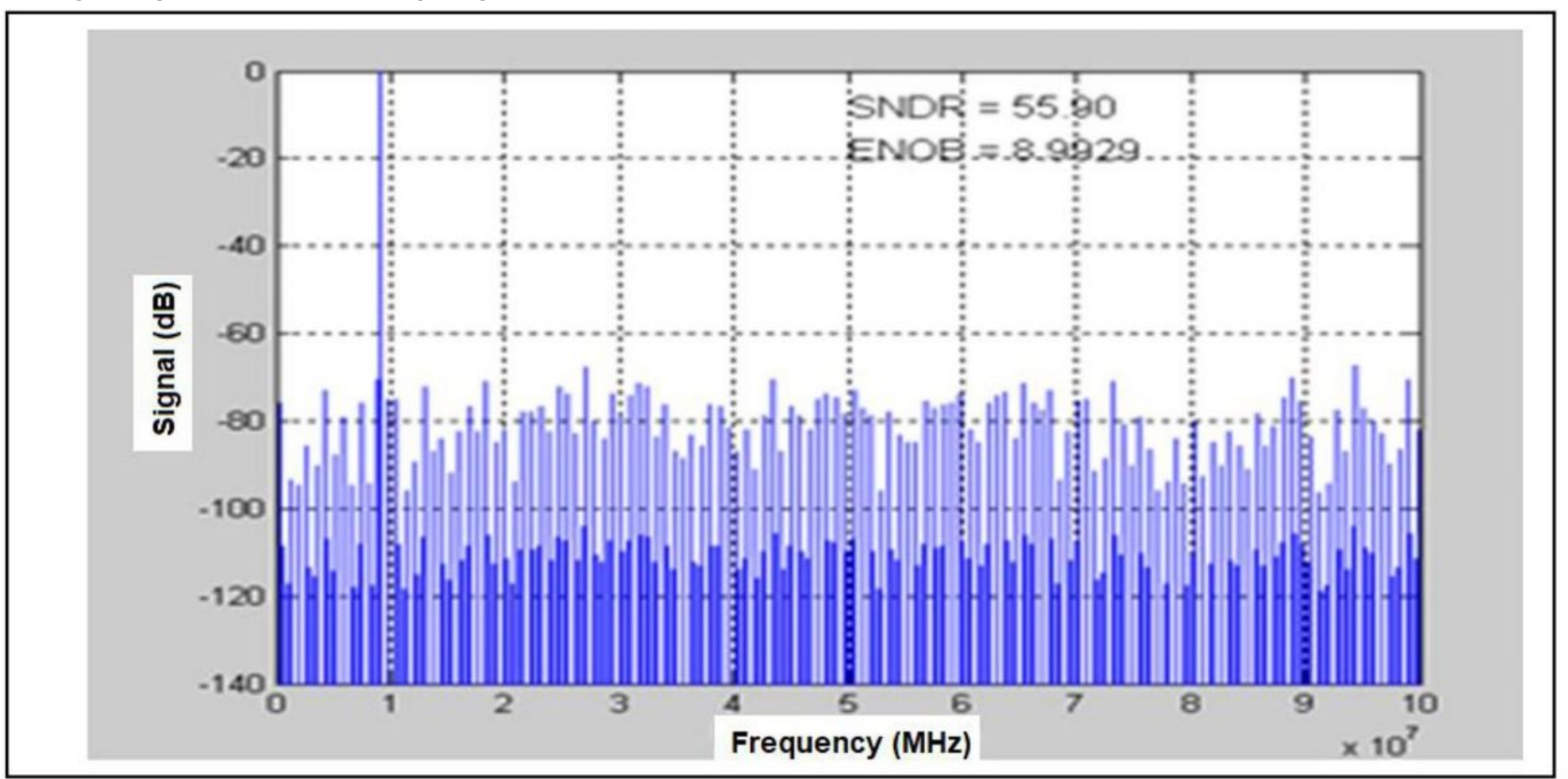

Figure 10

Obtained FFT spectrum of pipelined ADC 


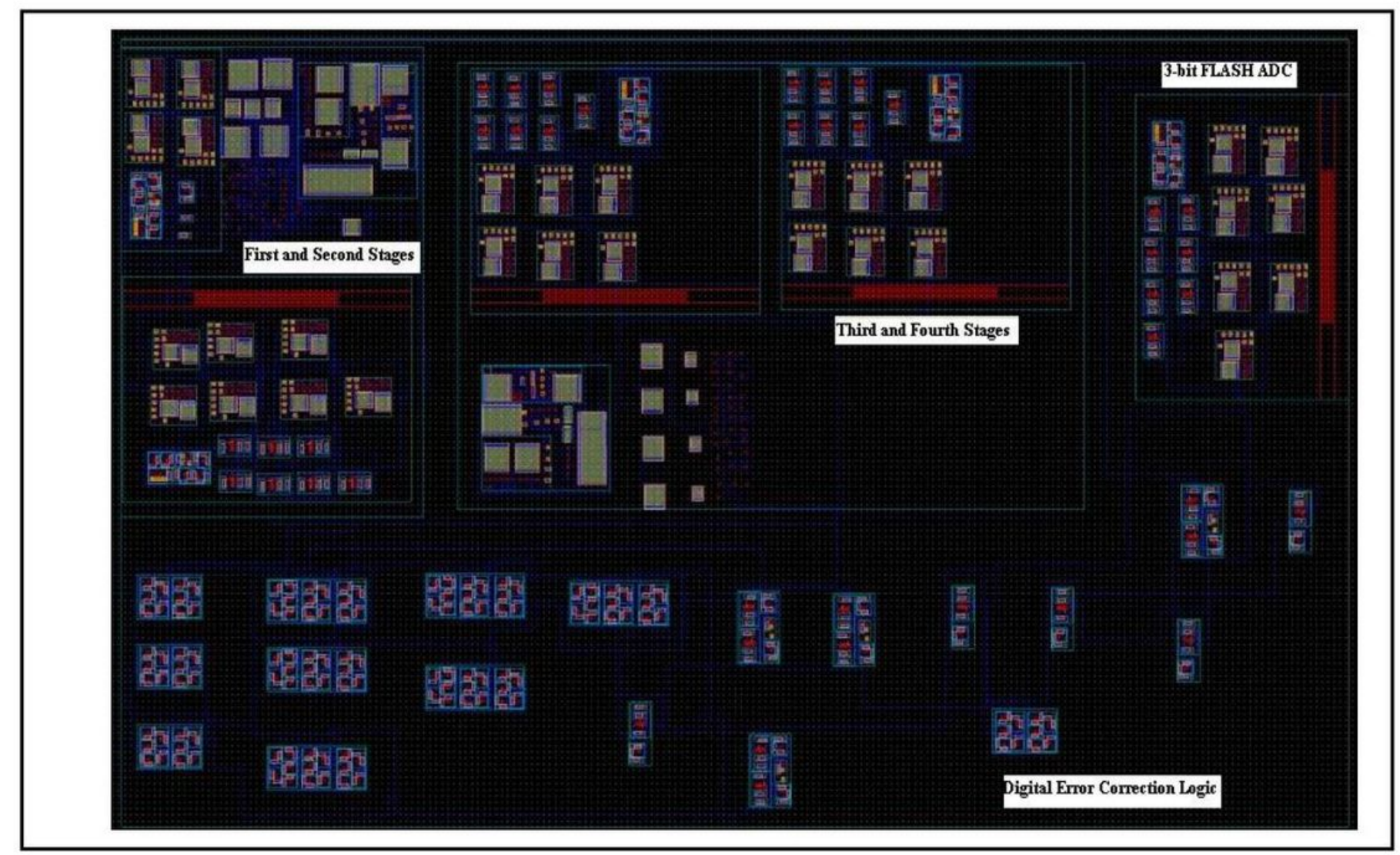

Figure 11

The layout of the 10-bit SHA less Pipelined ADC 